\section{Significação do consumo em botecos cariocas: uma análise da experiência na Mureta da Urca}

\author{
Fábio Francisco de Araujo, Thais Barreto Estrella e \\ Karla Andréa Dulce Tonini
}

\section{RESUMO}

O presente estudo parte da necessidade de se refletir e compreender o processo de construção de significados das práticas de consumo que emergem no contexto de bares e botecos a partir da articulação entre cultura e consumo. Para isso, optou-se por utilizar técnicas do método etnográfico, como observação participante, conversas informais e entrevistas no Bar e Restaurante Urca, considerado Patrimônio Cultural da Cidade do Rio de Janeiro. A análise é feita sob a perspectiva do Consumer Culture Theory (CCT). As observações permitiram formar diferentes categorias de análise, as quais emergiram da ambientação estruturante das interações e do próprio discurso dos frequentadores a partir do uso dos espaços que são o bar, o restaurante, a mureta e a "pobreta". Os resultados apontam que o processo de significação pelos diferentes indivíduos frequentadores extrapola a lógica prática e objetiva que poderiam nortear as motivações de escolha para o consumo dos produtos e serviços. Esse processo favoreceu uma análise mais aprofundada sobre a produção de sentidos a partir da "teia de significado" que decorre das práticas no espaço pesquisado.

Palavras-Chave: significados do consumo; cultura e consumo; lazer; boteco carioca; patrimônio imaterial.

\section{Meaning of consumption in cariocas' bars: an analysis of the experience in Mureta da Urca}

\section{ABSTRACT}

The present study starts from the need to reflect and understand the construction process of the meanings of consumption practices that emerge in the context of bars and "botecos" (small bars) from the combination between culture and consumption. To do that, it was decided to use techniques of the ethnographic methods, such as participant observation, informal conversations and interviews at the Bar and Restaurant Urca, establishment of this nature as Cultural Heritage of the City of Rio de Janeiro. The analysis was done from the perspective of the Consumer Culture Theory (CCT). The observations form different categories of analysis, which emerged from the structuring interactions and the own speech of the regular users of the places, which are the bar, the restaurant; the wall and the "pobreta". The results point that the process of signification by different individuals goes beyond the practical and objective logic that could influence the motivations of choice for the consumption of the products and services. This process favored a more detailed analysis of the production of senses from the "web of meaning" that derive from the practices in the searched area.

Keywords: meanings of consumption; culture and consumer; leisure; boteco carioca; intangible heritage.

Recebido em: 29/09/2019 Revisado em: 03/02/2020 Aprovado em: 17/09/2020

Check for updates

Fábio Francisco de Araujo (iD,

Universidade Federal do Rio de Janeiro, Brasil

Doutor em Administração, Pontifícia Universidade Católica do Rio de Janeiro, Brasil

fabiofdearaujo@gmail.com

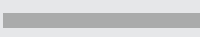

Thais Barreto Estrella (iD, Universidade Federal do Rio de Janeiro, Brasil

Mestre em Nutrição, Universidade Federal do Rio de Janeiro, Brasil

thais.estrella@hotmail.com

Karla Andréa Dulce Tonini iD,

Universidade Federal do Rio de Janeiro, Brasil

Mestre em Administração,

Universidade do Grande Rio, Brasil

karlatonini@yahoo.com.br 


\section{Introdução}

A partir de 2012, os botecos cariocas foram reconhecidos como Patrimônio Cultural da Cidade do Rio de Janeiro por considerar que esses estabelecimentos são locais de socialização democrática e que traduzem o "espírito carioca" de reunir e festejar. Nesse sentido, em meio às comemorações dos 450 anos da cidade foi editado o Decreto Municipal 36605/2012, atribuído o reconhecimento de 14 estabelecimentos, entre bares e botequins tradicionais, a categoria de Patrimônio Cultural da capital carioca, elevando-os à condição de Patrimônio Imaterial.

O presente estudo parte da necessidade de se refletir e compreender o processo de construção de significados das práticas de consumo que emerge no contexto de bares e botecos a partir da articulação entre cultura e consumo. Esses estabelecimentos são popularmente conhecidos como "botecos", que representam espaços que atuam como palco das representações da vida social, artísticas, políticas e do lazer, expressas por meio da sociabilidade estabelecidas durante as práticas de consumo que neles ocorrem (Sebadelhe, 2016).

Nesses espaços sociais as interações ocorrem em meio ao consumo de bebidas e alimentos, onde a variedade alimentar perpassa a vida cotidiana do frequentador. Nesse sentido, os bares e os botecos se tornam um ambiente atrativo no processo de construção de significados sociais que tangencia a própria imagem da cidade.

Maclnnis e Folkes (2010) publicaram um artigo teórico no Journal Consumer Research no qual estabelecem uma discussão sobre o melhor enquadramento das pesquisas em comportamento do consumidor. Deacordo com as autoras, a área do comportamento de consumo é multidisciplinar e, nesse sentido, dialoga com diferentes campos do conhecimento, incluindo a análise do consumo como um fenômeno cultural. Neste estudo, o caráter simbólico do consumo está relacionado à rede de associações culturais a que os indivíduos estão inseridos, construídas nos espaços de interação social, experiência e sociabilidade (Araujo \& Rocha, 2016).

Considerando que a construção do conhecimento é desenvolvidaà luz das percepções dos indivíduos que vivem no contexto da realidade pesquisada, utilizou-se nesta pesquisa técnicas presentes no método etnográfico. Neste sentido, empregou-se a observação participante, conversas informais e entrevistas em profundidade com frequentadores do campo estudado. De acordo com Elliott e Jankel-Elliott (2003), as observações e as entrevistas que se pode fazer no ambiente analisado configuram-se como técnicas adequadas para o acesso ao entendimento do fenômeno social a partir do ponto de vista daqueles que estão inseridos no campo.

A pesquisa de campo foi realizada no Bar e Restaurante Urca, popularmente conhecido como "Mureta da Urca", para compreender os significados atribuídos à experiência de consumo no espaço investigado. O bar selecionado é considerado Patrimônio Cultural da Cidade do Rio de Janeiro, conforme o Decreto Municipal RJ 36.605/2012. A pesquisa de campo se consistiu em observação participante, conversas informais e entrevistas, sendo realizada aos finais de semana durante um período de um 
semestre, permitindo avançar no processo de construção do conhecimento dos significados atribuídos à experiência de consumo obtidas no próprio espaço em momentos de interação dos frequentadores. Os achados da pesquisa indicam que as características do lugar e os aspectos destacados pelos frequentadores contribuem para formar um conjunto de significados que juntos expressam o capital simbólico do espaço, ultrapassando as razões práticas e funcionais que motivam o consumo de seus produtos e serviços.

\section{Cultura e Consumo}

O consumo vem sendo estudado a partir da "lente da cultura" com o objetivo de tentar entender o comportamento e a dinâmica que decorrem das ações dos consumidores, do próprio mercado e os significados culturais envolvidos (Arnould \& Thompson, 2005, p. 869). Slater (2002, p. 17) sublinha que "o consumo é sempre e em todo lugar um processo cultural, mas 'cultura do consumo' é singular e específica". O consumo compreendido a partir da cultura é percebido como socialmente construído e sempre envolve significados que se articulam com as relações sociais em um determinado contexto, pois são partilhados, transformados e específicos de cada sociedade. Assim, trata-se de um acordo social dependente da relação cultural com os recursos sociais, que considera os estilos de vida significativos, as dimensões simbólicas e os recursos materiais definidos pelos mercados.

Ao privilegiar a dimensão simbólica do consumo, este estudo se situa na linha de estudos em marketing conhecida como CCT - Consumer Culture Theory. De acordo com Arnould e Thompson (2005), as pesquisas na área de Consumer Culture Theory (CCT) em comportamento do consumidor não se tratam de uma perspectiva teórica única. Tratam-se da reunião de diferentes perspectivas teóricas que investigam os relacionamentos dinâmicos entre as ações do consumidor e o mercado, articulando-os a significados culturais do contexto em que a prática de consumo se desenvolve. Nesse sentido, os pesquisadores da CCT tomam parte em uma orientação teórica comum sobre temas de estudos do consumo a partir da realidade cultural, considerando toda sua complexidade e relacionando-a aos seus fenômenos de estudo. Assim, como pontuado por Gaião, Souza e Souza Leão (2012), o CCT é um campo independente de estudo sobre o fenômeno do consumo, pois este integra um sistema de valores compartilhados socialmente que, apesar de sua pluralidade de enfoques teóricos e de objetivos de pesquisa, explora os significados culturais a partir das experiências cotidianas e simbólicas que ocorrem no contexto social e que vão constituindo o comportamento do consumidor.

Cabe ainda ressaltar, tal como já tinha sido sublinhado por Geertz (1973), Arnould e Thompson (2005, p. 869) também destacam que a cultura representa "o próprio tecido da experiência, do significado e da ação". Kleine III e Kernan (1988) esclarecem que o termo "significados" pode ser usado para dirigir sentido a um conjunto de percepções que possibilita ao indivíduo criar categorias estruturantes de experiências a partir de seu modo de ver 
a realidade. Ahuvia (2005) esclarece que quando se analisa os significados não se busca compreender isoladamente as práticas, os comportamentos ou mesmo o consumo dos bens e de atividades, mas sim a produção de sentidos que são conferidos a tais consumos por quem os interpreta. Essa significação é, por diferentes razões, resultado de processos de significações individuais, difíceis de serem transferidos, mas que atribuem sentido às práticas de consumo.

Desta forma, o consumo está relacionado à significação, que se configura como conjunto culturalmente particular e fundamentalmente arbitrário de associações interligadas que possibilita ao sujeito extrair pelas experiências das práticas de consumo tanto significados pessoais quanto sociais (McCracken, 1988; Solomon, 2016; Matsunobu, 2018). Não importando como esses significados sociais são promovidos pelo meio, o consumidor interpreta o bem consumido e cria uma história que lhe traz uma significação especial (Araujo, Cherchiaro, Silva, \& Espíndola., 2020).

Como destacado por Carù e Cova (2003), as práticas de consumo não são apenas mediadas pelo mercado, mas incluem outras influências que decorrem da vida cotidiana, relações sociais, valores culturais e, nesse sentido, as experiências são muito mais decisivas para o comportamento do consumidor do que tão somente as ações mercadológicas. Desse modo, como ressaltado por Kozinets (2001), as práticas de consumo são orientadas pela criação de sentidos resultantes das experiências individuais e cotidianas. É nesse contexto que as práticas de consumo vão ao encontro do referencial do CCT, pois as dimensões simbólicas, ritualísticas, estéticas e hedônicas são frutos de signos culturais e determinantes para ações comportamentais dos indivíduos.

Assim, os aspectos simbólicos atribuídos a objetos e a outras práticas de consumo ocorrem dentro do seio da sociedade onde o consumidor vive suas experiências culturais (Hall, 1997). Conforme observado no estudo de Araujo e Tinoco (2015), no contexto cultural, os valores conferidos às práticas de consumo são compartilhados socialmente. Segundo Barbosa (2004), a dimensão cultural do consumo pode atuar como uma forma de expressão simbólica que permite aos indivíduos construir e afirmar seus respectivos selfs, possibilitando que as práticas de consumo representem um caminho para o processo de diferenciação social. Holt (2002) contribui para esse debate pontuando que os significados atribuídos às práticas de consumo individuais decorrem do contexto social e cultural em que o indivíduo se insere e, dessa forma, o comportamento de consumo funciona como um recurso importante de construção, de manutenção e até de modificação da identidade social. Luedicke, Thompson e Giesler (2010) pontuam ainda que a identidade dos consumidores é culturalmente associada à moral social e, por essa razão, os significados ideológicos compartilhados no seio da sociedade podem ser determinantes para as escolhas, para o comportamento dos indivíduos, e para as práticas de consumo.

Os espaços de interação social possuem bastante relevância para os estudos de comportamento do consumidor (Araujo \& Rocha, 2016). No entanto, a própria noção do que seriam esses espaços ainda se encontra em aberto, seja nas discussões acadêmicas ou nas práticas de mercado, e seu significado pode variar substancialmente considerando as práticas culturais 
em diferentes sociedades. Seriam esses espaços de socialização ambientes de lazer? Locais para passagem de tempo livre? Lugares propícios para reflexões e ideias? O fato é que esses ambientes são espaços de encontros que promovem a interação social e podem conjugar todos os exemplos mencionados. Portanto, trata-se do lugar onde ocorrem diversas trocas simbólicas, sofrendo apenas algumas variações em função do grupo social e do grupo etário, assim como da cultura em que os indivíduos se inserem (Araujo, Turano, \& Vieira, 2019).

Barbosa e Campbell (2006) destacam que o mercado global contribuiu para que as lógicas que criam necessidades para o uso de bens e serviços fossem partilhadas para além das fronteiras físicas. Percebe-se que nesse movimento houve uma articulação profunda entre consumo e cultura, pois todo o processo de consumo somente fará sentido dentro de um sistema cultural. Diante do fenômeno global, notou-se uma ampliação pelo alargamento da lógica de aquisição de bens e serviços a partir dos compartilhamentos de informações locais sobre uso de bens e coisas que, invariavelmente, transferem signos culturais que são (re)significados nos espaços em que chegam e podem influenciar o comportamento de consumo.

Em sua clássica obra 'A Distinção', Bourdieu (1979) sublinhou que as práticas de consumo podem indicar a construção de formas de identificação social. Para o autor, esse fenômeno pode ocorrer quando um determinado grupo social ou mesmo um indivíduo evidencia sua capacidade de consumo por meio da ostentação. Desse modo, de acordo com Bourdieu (1979), as práticas de consumo podem expressar uma forma de distinção social.

\section{A valorização do Boteco Carioca}

Segundo Mello (2003), a noção atual de boteco se desenvolveu mediante um processo. $\mathrm{O}$ autor ressalta que ao estudar o tema esbarrou nos bares e suas diferentes categorias, destacando que ao longo tempo se chegou à noção de boteco como é conhecido hoje. Mello (2003) lança luz ao fato de que o boteco assume um lugar de destaque tanto no cenário carioca quanto para própria imagem da cidade, levando, inclusive, à publicação de um livro, intitulado "Guia Rio Botequim". De acordo com o autor, o boteco, ou botequim, é uma espécie de bar, mas com especificidades próprias em função do público, da natureza do cardápio, da utilização do espaço, da localização, e de sua influência na chamada boemia carioca que se integra a vida sociocultural carioca.

Segundo Houaiss e Villar (2001), o vocábulo boteco em algumas vezes aparece como sinônimo de botequim, outras vezes como um diminutivo de botequim, ou trata-se de um botequim de qualidade inferior. Mello (2003) ressalta que alguns estudos trata o boteco como um espaço simples, sem sofisticação, muitas vezes um negócio de família, no qual os "fregueses" adquiriam insumos, faziam a primeira refeição do dia, o café com leite e pão com manteiga, ou passavam para almoçar, ou ainda para reunir os colegas de trabalho a fim de tomar uma cerveja ou cachaça e comer um petisco. Assim, o boteco é considerado por alguns como extensão do lar. 
Botecos ou botequins são termos próprios que emergem na cidade do Rio de Janeiro para designar antigas casas de abastecimento e revenda de bebidas, principalmente alcoólicas, fármacos e gêneros alimentícios em geral, que são conhecidos por Boticas em Portugal e por Bodegas na Espanha (Sebadelhe, 2016). Segundo Mello (2016), ao longo do tempo, em decorrência da frequência desses espaços na tradição carioca, o conceito de boteco poderia ser mais abrangente como sendo bares distintos, mas que variam desde casas de pasto do fim do século XIX à uisqueria dos anos 1970, permeado por cafés, biroscas, boticas, armazéns, tabernas e adegas, entre outros. A similaridade desses estabelecimentos está no fato de servirem bebida alcoólica, terem uma ambiência típica com balcões, atendentes e predominância da clientela masculina, além de um tipo de sociabilidade informal e descontraída, o que distingue esses estabelecimentos dos restaurantes e boates.

No passado, os botecos não tinham mesas, as pessoas eram atendidas pelo próprio dono do recinto no balcão e consumiam em pé. O sistema de pagamento ocorria apenas por dinheiro, que deveria ser à vista, porém também era possível comprar fiado. Os botecos foram ganhando cada vez mais espaço e se adaptando a um público cada vez maior e heterogêneo conforme a cidade e a frequência nesse tipo de barzinho foi crescendo (Mello, 2003). Contudo, é importante destacar que esse formato inicial, no qual os clientes são atendidos no balcão e consumiam de pé ali mesmo, ainda existe tanto em botequins da área central da capital quanto dos subúrbios e dos interiores, como também em lugares que demandam fluxo rápido, como rodoviárias e estabelecimentos em regiões comerciais (Mello, 2016).

Outra característica importante da sociabilidade da origem dos botecos é o fato de que no século XVIII esses locais também eram utilizados para reuniões a portas fechadas, jogos de cartas e dados, discussões políticas e religiosas, entre outros temas proibidos para época, tornando esses locais redutos para conspirações de ideias e posicionamentos políticos. Isso fez com que em maio de 1808, o Intendente Geral da Polícia da Corte, Paulo Fernandes Viana decretasse o fim do expediente desses botequins logo após as $22 \mathrm{hs}$ para evitar aglomerações de ociosos e badernas. Esta lei traz um dos primeiros registros do termo botequim em terras brasileiras, sendo assim, desde a vinda da Família Real, o botequim nasceu estigmatizado como estabelecimento de má qualidade, enquanto os frequentadores eram considerados de baixa classe social (Mello, 2016).

Entre 1870 e 1991, vários quiosques surgiram na cidade com características de pequeno porte, em formato hexagonal, com bancadas ao redor. Eram locais lamacentos e exalavam mau odor devido a restos de comidas no chão, doses para o "santo", além de cuspidelas (Mello, 2016). O que nos remete associação com o termo "pé sujo", comumente utilizado para os botequins no Rio de Janeiro até os dias atuais.

A transformação da configuração física dos botecos se deu a partir de meados do século XIX, com a modernidade, a reforma urbana de Pereira Passos e quando a cerveja passou a ser a bebida de maior consumo nacional. Sendo assim, os botecos e bares do Rio de Janeiro passaram abrir com estruturas mais sofisticadas, aproximando-se dos modelos dos cafés parisienses, mas mantendo as estruturas nascentes de formato hexagonal 
e com bancadas ao redor. Nesse ambiente também aparecem as primeiras iguarias dos botecos, tais como sardinhas fritas e bolinhos de bacalhau; além de café com leite e pão com manteiga. Atualmente só existem dois bares desse modelo dentro do parque do passeio público (Mello, 2016).

Porém, algo que a modernidade não conseguiu excluir da essência dos botecos é o fato de esses estabelecimentos reunirem pessoas. Esses locais emergem como espaços que favorecem a sociabilidade que ocorre em meio ao consumo de um chope gelado ou das demais bebidas, petiscos ou comidas de saber tradicionalmente caseiro. Além da comida, a sociabilidade é favorecida por meio da oferta de outros atrativos, tais como: música, jogos etc., o que tornam esses locais de consumo singulares, pois a experiência é fundamental para o entendimento do significado do botequim no cenário carioca (Sebadelhe, 2016).

\section{Botecos como espaços de interação e sociabilidade}

Pesquisas anteriores apontam uma relação de proximidade entre os espaços de interação, alimentação e determinados universos culturais (Adade, 2013; Ahuvia, 2005; Araujo, Bitar, Santos, Baião \& Silva, 2019; Barbosa, 2004; Barbosa, 2010; McFerran, Dahl, Fitzsimons, \& Morales, 2010; Medeiros, 2004; Vargens \& Monte, 2001). A comida em eventos, como bares ou rodinhas de sambas cariocas reproduzem e atualizam a dinâmica da sociabilidade no Rio de Janeiro, refletindo as mais fortes expressões de tradição carioca. Nesse sentido, o compartilhar do comer, do beber, da companhia, simbolizam a renovação da energia de todos os que convivem e participam dos encontros, considerando formas que equivalem ao bem viver e, de outro lado, contribuindo para construir, preservar, comunicar e reforçar memórias individuais e coletivas que emergem das interações sociais e culturais (Araujo, Bitar, Santos, Baião \& Silva, 2019). Vargens e Monte (2001) estabelecem uma relação entre a comida e os espaços de encontros para beber e cantar, pontuando que tal relação foi fundamental para estabelecer uma conexão entre reunião e resistência na passagem do período escravocrata nos espaços boêmios do Rio de Janeiro, constituindo parte da identidade da cidade que está presente como expressão da cultura e da prática do consumo de lazer.

Segundo Araujo, Rocha, Chauvel e Schulze (2013), as práticas de consumo que envolvem atividades de lazer passaram por mudanças gradativas no decorrer do tempo. Para os autores, o significado do consumo de lazer não remete apenas à diversão, ao prazer ou ao relaxamento, pois passou a incluir práticas comportamentais e aquisições de bens, tais como cursos desejados de língua, informática ou formação alternativa, aquisição de livros, passar tempo estudando em bibliotecas ou em outros espaços, aquisição comercial de vídeos com filmes ou músicas, entre outras formas de consumo. De acordo com Taschner (2000), somente no século XX o consumo de lazer passou a ser associado ao prazer e à diversão, assumindo uma perspectiva mais abrangente. Cabe pontuar que o consumo de atividades que remetem à diversão possui apelos simbólicos, os quais 
podem conduzir os consumidores a articularem emoção à experiência de consumo, proporcionando novas possibilidades de experimentação da atividade (Holbrook e Hirschman, 1982).

O lazer contemporâneo é, em grande parte, mediado pelo consumo de atividades que nascem de práticas culturais socialmente construídas e compartilhadas, assumindo características localizadas em grupos ou locais específicos (Araujo \& Rocha, 2016). Nesse sentido, uma atividade de lazer abrange todo um conjunto de imagens, símbolos, valores e atitudes que se desenvolveram com a modernidade, passando a orientar pensamentos, sentimentos e comportamentos de segmentos dentro de um contexto cultural (Taschner, 2000).

Em relação à cultura de bar que se desenvolveu como uma forma de lazer típica da cidade do Rio de Janeiro, observa-se que tal fenômeno foi resultado de uma dinâmica própria, que se encaminhou pela articulação da cultura local e as opções de consumo, tendo vem vista que a cidade se desenvolveu como ponto de encontros de artistas, pensadores, articuladores políticos, turistas, migrantes e imigrantes (Mello, 2003). Essa forma de encontro reverbera a boemia típica do carioca que traz consigo os botecos, que representam os locais dos encontros do boêmio carioca. Nesses estabelecimentos, ao longo dos anos foram sendo construídas relações e interações, ocorreram trocas culturais e se desenvolveram os símbolos e significados próprios que hoje são representativos desses espaços (Silva, 2011). Esse fenômeno comportamental, característico do Rio de Janeiro, coloca os bares e botecos como palco das representações das vidas social, artística e política expressadas em formas de sociabilidade ocorridas durantes as práticas de consumo nesses estabelecimentos (Sebadelhe, 2016). Assim, as experiências de consumo e o ambiente de suas interações favoreceram a construção de uma identidade própria dos bares e botecos, fazendo emergir um conjunto de significados representativos do chamado "espírito carioca".

A criação do concurso Comida di buteco na cidade de Belo Horizonte teve o intuito de valorizar o que se denominou de "baixa-gastronomia", ou seja, aquilo que é produzido nos botecos, comida simples da culinária regional brasileira, preparada por cozinheiros que vivem no anonimato. Desta forma, houve um movimento de valorização desse tipo de estabelecimento, e com isso os pequenos botecos se viram diante de novos desafios para desenvolver e sustentar o negócio, tais como: profissionalização, contratação de chefs de cozinha, investimento em comunicação de massa, criatividade e valorização da comida de raiz com certa sofisticação dessa gastronomia. 0 evento chegou à cidade do Rio de janeiro em 2008. Em linhas gerais, o evento proporcionou o incremento dos negócios e a ampliação no faturamento (Adade, 2013).

Desta forma, vale compreender o termo "baixa gastronomia" e sua relação com comida de boteco. Segundo colocam Ferreira, Valduga e Bahl (2016), a gastronomia pode ser compreendida como resultado da vivência da cultura local a partir da sua articulação com a atividade cultural de uma localidade. Nesse contexto, de acordo com os autores, a baixa gastronomia emerge com um conceito de gastronomia que abrange comidas de caráter 
caseiro e popular, em porções bem servidas, em estabelecimentos simples. Assim, a compreensão da baixa gastronomia passa por oferta de alimentação de raízes populares e aperitivos de preparo caseiro ou típicos de uma região, em espaços que valorizam a informalidade e tradições culturais (Costa, Salazar, Alves, \& Silva, 2019). Esses estabelecimentos possuem aspectos que também são característicos dos botecos, uma vez que oferecem pratos saborosos, populares e simples, com o atendimento informal, valorizando a interação entre as pessoas no ambiente, além de oferecer pratos com bom custo/benefício (Adade, 2013; Costa et al., 2019; Sebadelhe, 2016).

Se as práticas de consumo estão pautadas na acolhida, na troca e na interação com e entre os frequentadores, pode-se dizer que os botecos são espaços concretos de sociabilidade, experiências e compartilhamento de práticas sociais (Costa et al., 2019). Desta forma, o significado do boteco ultrapassa a simples descrição de um bar, assumindo uma perspectiva de que esse espaço se estabeleceu e desenvolveu uma identidade própria a partir dos significados que lhe foram constituindo, os quais conferem sentidos próprios ao estilo de vida do carioca frequentador desses estabelecimentos. Esses significados assumem o papel de símbolo que dialoga com dimensões da hospitalidade pública e privada no contexto das interações sociais, seja para acolher ao conhecido ou àquele que surge e é recebido para integrar e compartilhar o ambiente (Ferreira, Valduga, \& Bahl, 2016).

\section{Método}

O presente artigo está epistemologicamente inserido no paradigma interpretacionista, filiando-se à área de pesquisa denominada Consumer Culture Theory (CCT) em comportamento do consumidor (Arnould \& Thompson, 2005). A linha de investigação proporcionada pela área de pesquisa da CCT contribui para interpretar como os indivíduos interagem e constroem significados no contexto cultural no qual se inserem, buscando traduzir a realidade construída pelos sujeitos a partir de suas práticas de consumo.

A presente pesquisa se valeu de métodos de inspiração etnográfica para etapa de coletas de dados, os quais já estão sendo adotados por pesquisadores que investigam o fenômeno do consumo com relativa frequência (Araujo \& Rocha, 2019; Arnould \& Wallendorf, 1994; Barbosa, 2010; Matsunobu, 2018; Tureta \& Alcadipani, 2011). O método etnográfico oferece técnicas que podem ser utilizadas para a compreensão do cenário objeto de estudo, que consistem na observação e em entrevistas (Stacey, 1977). A observação é uma técnica que exige alto grau de envolvimento direto com os indivíduos do grupo pesquisado, isto é, requer uma imersão no grupo que se quer pesquisar para extrair os elementos incorporados pelos indivíduos e, assim, obter a descrição densa daquilo que se fala (Geertz, 1973). De acordo ainda com Geertz (1973), no contexto da observação participante, o pesquisador se integra ao grupo e se relaciona diretamente com aqueles que o compõe, com o objetivo de compartilhar a vida social e compreender a partir da visão deles as dinâmicas sociais sobre o fenômeno de estudo. 
Assim sendo, esta pesquisa utilizou a perspectiva etnográfica, realizando observação participante com técnicas de entrevistas, conversas informais e registros fotográficos realizadas no Bar Urca, popularmente conhecido como Mureta (ou Muretinha) da Urca (Oliveira, 2006; Elliott \& Jankel-Elliott, 2003). A seleção do Bar Urca se deu em razão da grande adesão do público conforme recorrentemente divulgado na mídia, por facilidade de acesso dos pesquisadores e, sobretudo, por esse bar ser um dos quatorze estabelecimentos comerciais classificados como Patrimônio Cultural da Cidade do Rio de Janeiro e, nesse sentido, considerados Patrimônios Imateriais da cidade, indicados com tais pelo Decreto Municipal RJ 36.605/2012. Nesse contexto, o Bar e Restaurante Urca representa uma legítima expressão da sociabilidade carioca, no qual o bar é palco de interação entre os frequentadores, os quais constroem coletivamente os significados relativos a essa prática de consumo.

Foram realizadas visitas ao Bar Urca para reconhecimento do contexto local e suas particularidades. A observação participante ocorreu às sextas-feiras e aos sábados, iniciando-se por volta das 15h e com o término variando entre $18 \mathrm{~h}$ ou $19 \mathrm{~h}$, sendo realizada durante os meses de julho a novembro de 2018, considerando tanto estabelecimento do Bar Urca como o espaço da conhecida murada, a popular mureta. Os dados coletados durante a observação participante foram registrados nos cadernos de campo, onde também foram registradas as conversas informais, além de se realizar outros registros por meio de fotografias. Ainda durante a observação, alguns frequentadores e atendentes do Bar e Restaurante Urca foram selecionados para serem entrevistados. A abordagem ocorreu durante a prática do consumo na mureta ou no restaurante com frequentadores que se mostraram abertos para conversar. Alguns destes, além de participar das conversas informais, foram convidados para participar da etapa de entrevistas, que foram agendadas para outra data na própria mureta. Foram entrevistados um total de dezenove pessoas. Para realização das entrevistas, utilizou-se um roteiro semiestruturado desenvolvido a partir de fatores identificados na literatura consultada e da etapa inicial da própria observação participante. Durante a condução da entrevista, foram incluídas novas perguntas para explorar questões trazidas pelos próprios entrevistados, aprofundando aspectos que ainda não tinham sido identificados nas conversas anteriores. As respostas às perguntas abertas se mostraram altamente reveladoras, pois permitiram explorar perspectivas individuais dos diversos atores envolvidos no mesmo fenômeno investigado (Rubin \& Rubin, 2005). As entrevistas tiveram duração de aproximadamente trinta minutos cada e ocorreram no próprio ambiente do Bar e da Mureta, sendo integralmente gravadas e transcritas para análise.

A partir da reunião dos dados coletados (Oliveira, 2006; Elliott \& Jankel-Elliott, 2003; Strauss \& Corbin, 2008), buscou-se perceber aspectos como o significado do encontro, os simbolismos atribuídos ao lugar, as formas de consumo dos alimentos e bebidas, as formas de organização dos consumidores no espaço da mureta e os aspectos de sociabilidade na interação entre as pessoas. A análise dos dados consistiu nas seguintes etapas: (1) imersão no espaço estudado para uma análise do contexto do fenômeno analisado; (2) desenvolvimento de um conjunto de categorias 
iniciais e temas a partir da análise conjunta das observações, conversas informais, entrevistas e fotografias; (3) identificação nas transcrições dos discursos dos informantes correspondentes à categorias identificadas na literatura; (4) identificação de novos aspectos das categorias e temas que surgiram do campo; (5) releitura do diário de campo e transcrições, inclusive revisando continuamente a teoria para verificar as categorias agrupadas; (6) seleção de novas seções dos discursos dos informantes correspondentes às categorias identificadas; (7) verificar novamente os dados com base nas premissas da CCT e na pesquisa de campo sobre criação de significado por meio das práticas de consumo no Bar e Restaurante Urca para confirmar as categorias emergentes. O material coletado foi interpretado conjuntamente e durante o processo de pesquisa, considerando que a análise foi realizada em etapas, utilizando-se da técnica de comparação constante (Strauss \& Corbin, 2008).

O estudo partiu da necessidade de se refletir e compreender o processo de construção de significados atribuídos à experiência de consumo proporcionada pelo espaço da Mureta da Urca a partir da articulação entre cultura e consumo. Vale lembrar que os "botecos" são lugares ricos em produção de significados, o que pode justiçar o decreto municipal que demarca alguns deles como patrimônio cultural da cidade, pois favorecem a sociabilidade entre os frequentadores ocorridas durantes as práticas de consumo nesses estabelecimentos (Barbosa, 2010; Sebadelhe, 2016). Segundo Mello (2016), as experiências de consumo e as interações sociais favoreceram a construção de uma identidade própria dos bares e botecos que fez emergir um conjunto de significados característicos desses estabelecimentos na cidade do Rio de Janeiro.

\section{Análise dos Resultados}

O objetivo da pesquisa foi compreender o processo de criação de significados por meio das práticas de consumo no Bar Urca. Os dados obtidos indicaram que entre os frequentadores da Mureta da Urca não há um único objetivo que seja unanimemente determinante para a ida e para as práticas de consumo que ali ocorrem. Embora se possa esperar que, dada a localização e a tipicidade do cardápio, alguma característica do lugar como a vista, a comida ou a bebida, fosse determinante aos frequentadores. Apesar dessas características terem sido recorrentemente citadas, os entrevistados apresentaram de forma individual outras características percebidas e significadas maneira própria. Como relatado em outras pesquisas, por exemplo, nos estudos de Appadurai (1990), Bourdieu (1979) e Ahuvia (2005), a valorização de algo ocorre de acordo com a percepção do individual de cada indivíduo. Assim, apesar dos aspectos motivacionais poderem ser construídos a partir de processos interacionais entre os indivíduos, os apelos simbólicos tocam em cada indivíduo de maneira própria. Nesse sentido, as características do lugar e os aspectos que os entrevistados destacaram contribuem para formar um conjunto de significados que juntos expressam o capital simbólico dos frequentadores do espaço. 
O Bar e Restaurante Urca é um estabelecimento localizado na esquina da rua Cândido Gaffrée, situado em frente a Baia de Guanabara e próximo à entrada do histórico Forte São João. O estabelecimento possui dois espaços distintos: o restaurante e o bar. Possui uma entrada lateral para o restaurante que fica no segundo andar do local e tem estrutura independente do bar que fica no térreo. Os ambientes do restaurante e do bar se diferenciam no layout, na decoração, nos serviços oferecidos e no cardápio. Já a parte do bar do estabelecimento, no térreo, é caracterizada por um balcão tradicional de boteco, com vitrine para exposição de salgados, freezers e banheiros separados por sexo. O bar não possui mobiliário para os clientes, que se utilizam da famosa mureta da Urca com extensão do bar, onde geralmente permanecem após fazerem os seus pedidos.

A primeira constatação que pode ser feita diz respeito à sociabilidade proporcionada pela escolha de ir à mureta da Urca, na qual o Bar Urca é integrado. $O$ fato das pessoas elegerem pontos de encontros em espaços como bares e restaurantes aparece fortemente relacionado ao desejo de passar o tempo livre socializando, hábito que, como mencionado por Mello (2016), é fortemente demarcado na cultura da cidade do Rio de Janeiro. De acordo com os estudos de Barbosa (2010) e Araujo et al. (2019), as associações entre a sociabilidade e a alimentação decorrem do prazer existencial do encontro e da interação entre os indivíduos.

As observações feitas sobre a mureta da Urca revelaram que os frequentadores são de diferentes faixas etárias, integrando jovens, adultos e indivíduos de terceira idade. Além disso, o espaço é muito frequentado por cariocas, alguns com bastante regularidade, tendo escolhido o ambiente como o local por excelência para suas experiências de lazer. Entretanto, cabe mencionar que a mureta da Urca também é muito frequentada por turistas nacionais e estrangeiros, que vêm ao Rio de Janeiro. Um turista brasiliense, em uma conversa informal com os pesquisadores, destacou a sua frequência ao lugar com uma forma de "sentir" a experiência da cidade, que para ele significa "estar" no Rio de Janeiro e, de modo mais profundo, naquele momento, significa pertencimento. Em suas palavras:

Toda vez que venho ao Rio de Janeiro tenho que vir aqui. Porque aqui, eu me sinto carioca... como se fosse nascido nessa cidade. Amo a Mureta da Urca porque faz parte do que sinto quando estou no Rio de Janeiro.

Outro exemplo no mesmo sentido é o caso de um jovem turista mineiro, estudante de mestrado, que reside em São Paulo desde o início da faculdade, e informou que sempre quando possível vem ao Rio de Janeiro para "escapar" de sua rotina intensa. Em conversa com os pesquisadores, o jovem destacou que conheceu a Mureta da Urca por um amigo carioca e se "encantou pelo lugar", pontuando que desde então a sua passagem pelo Rio se torna completa ao passar uma tarde tomando cerveja com os amigos no Bar Urca. Assim, o processo de significação pelos diferentes indivíduos frequentadores extrapola a lógica prática e objetiva que poderiam tangenciar as motivações de escolha para o consumo dos produtos e serviços oferecidos pelo Bar. Desse modo, o processo de significação favorece uma análise mais aprofundada sobre a produção de sentidos a partir da "teia de significado" (Geertz, 1973) que decorre das práticas de consumo no espaço estudado. 
As observações realizadas formam diferentes categorias de análise, que emergiram da ambientação estruturante das interações e do próprio discurso dos frequentadores a partir do uso dos espaços, a saber: (1) bar; (2) restaurante; (3) mureta; e (4) "pobreta". Essas categorias são detalhadas a seguir.

(1) Bar: Configura-se com um grande balcão, não possui mesas e cadeiras. Os frequentadores realizam o seu pedido ao atendente em pé e costumam ficar ali esperando no balcão ou seguem para calçada ao outro lado da rua para ficar conversando, enquanto aguardam o pedido. O bar pode ser dividido em três ambientes, a saber: primeiro, o caixa onde os pedidos são feitos e pagos; segundo, o balcão; terceiro, a calçada do outro lado da rua. Quando o pedido chega, os consumidores ou consomem em pé no balcão ou levam tanto a comida e a bebida para a calçada do outro lado da rua. Esse terceiro ambiente é efetivamente a própria mureta da Urca que, embora seja parte do espaço público, funciona com uma extensão do bar. Por não possuir mesas, os consumidores ficam de pé, sentados ou encostados na mureta, enquanto consomem e socializam com amigos e familiares.

O balcão do bar é grande, caracterizado por aparentar um tradicional balcão de boteco carioca, conforme descrito por Mello (2016), com vitrine para exposição de salgados e freezers para bebidas. O espaço físico é pequeno, sobretudo considerando o fluxo de frequentadores, fato que contribui para que os clientes optem por ficar do outro lado da calçada usufruindo do espaço da mureta. O bar possui dois banheiros, um para uso masculino e outro feminino.

O bar é inspirado pela culinária portuguesa, possuindo um cardápio com abundância em frutos do mar, peixes e pratos como bobó de camarão. Entre as comidas inspiradas na culinária lusitana, são oferecidos cozido à portuguesa, uma linha de pratos de bacalhau, entre outros. Os petiscos ofertados são pastéis (nos sabores de bacalhau, camarão e siri), empadas, sardinha frita, caldos de frutos do mar e de feijão. O cardápio do bar possui ainda outras opções, como: café expresso, pão na chapa, caldos, sanduiches, e bebidas, além de biscoitos salgadinhos, balas, chiclete, cigarro e outros que não estão no cardápio, mas estão expostos no balcão. Existem ainda alguns clientes que pedem, pagam e levam o pedido para casa, como se estivessem passando em uma lanchonete de bairro. 

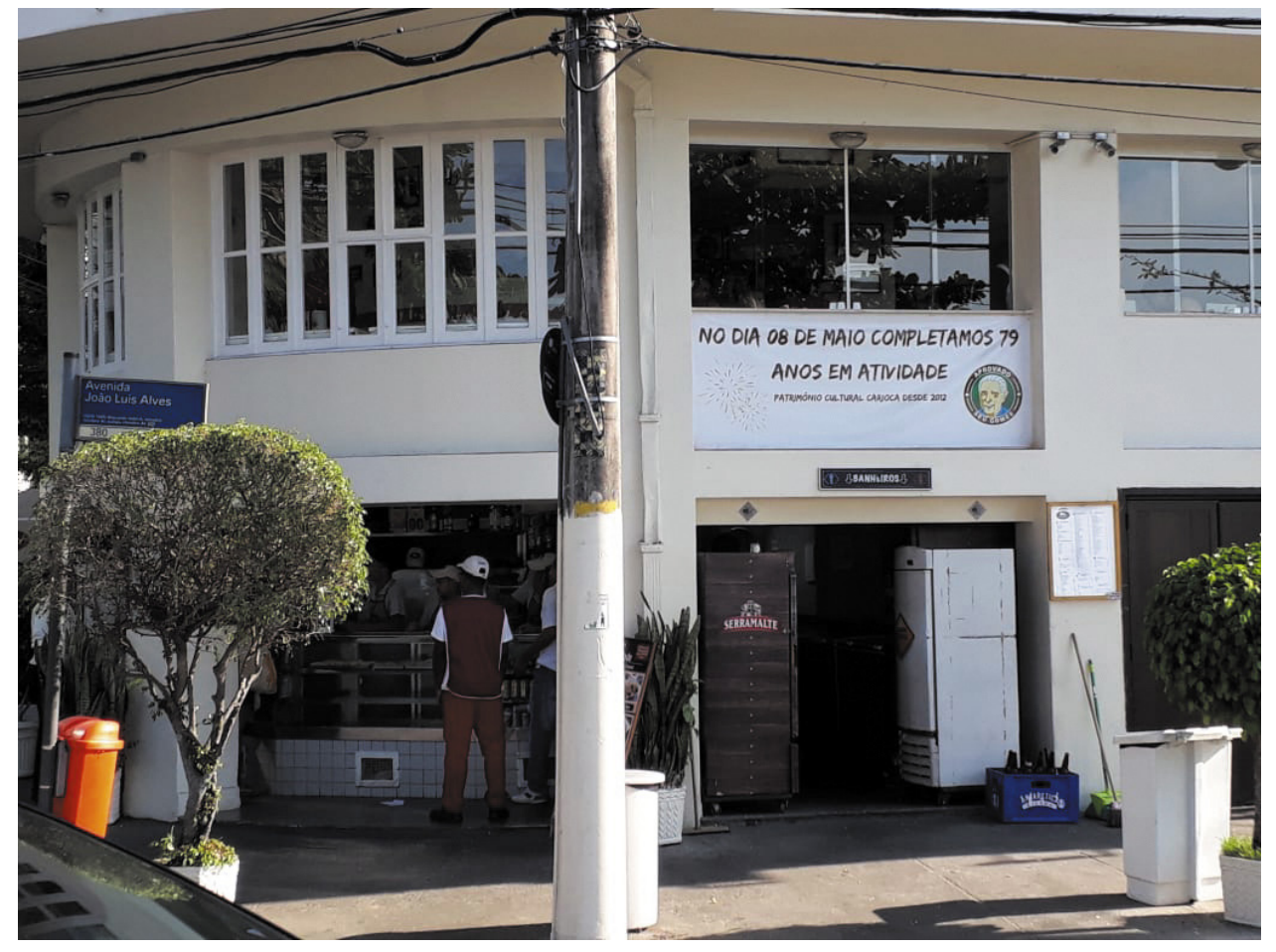

Fotografia 1. 0 Bar Urca

Fonte: Dados da Pesquisa (2018).

As pessoas compartilham das mesmas escolhas de consumo tais cmo: cerveja, petiscos (pastéis, empadas, bolinhos de bacalhau e sardinha frita) na maioria das vezes. O almoço normalmente é servido no restaurante, porém aqueles que chegam próximos ao final do horário do almoço pedem comidas que são vendidas no bar, como pratos executivos, por exemplo: Bobó de Camarão, Estrogonofe de Carne, Espaguete com Camarão, Bacalhau ao Brás e Risoto de Camarão, pratos servidos no restaurante e no bar. Entretanto, quando feitos no bar, diferentemente do que ocorre no restaurante, esses pedidos são servidos em pratos descartáveis.

(2) Restaurante: A entrada do restaurante é separada do bar (primeiro andar), a qual se encontra do lado direito do bar, como se pretendesse um distanciamento do aspecto mais informal que fica na calçada do bar. A entrada é bastante luxuosa, como se intencionasse gerar a ideia de um ambiente distinto. O restaurante fica na parte de cima do estabelecimento com uma grande janela que possibilita o acesso dos consumidores a vista da Baia de Guanabara mesmo dentro do local e, inclusive, para mureta da Urca. As paredes são pintadas de branco e possuem uma iluminação agradável. A organização do salão do restaurante se dá em mesas quadradas cobertas com toalha branca com opções de quatro, seis e oito cadeiras com forro de couro branco. Ao chegar na parte de cima do estabelecimento, o cliente se depara com a mesa posta, pratos e talheres já organizados sobre a mesa.

$\mathrm{Na}$ ambientação do restaurante são apresentados na parede alguns quadros de prêmios recebidos como de histórias de sucesso, agradecimento e depoimentos de clientes famosos que dão relevo à notoriedade do local. Essas mensagens indicam que o restaurante não é premiado apenas pela 
comida, mas também como um ponto turístico da cidade do Rio de Janeiro, reafirmando a ideia de que o restaurante não é frequentado só pela comida, mas também por seu caráter turístico. Isso nos leva a entender as falas dos informantes nas entrevistas, que pontuam que o Bar e Restaurante Urca não é só um espaço de comer, mas também de socializar e aproveitar o dia com seus amigos e familiares. Outro ainda, mencionou que o espaço é ideal para "turistar" com amigos no Rio de Janeiro, sugerindo o apelo turístico que o local possui entre os frequentadores.

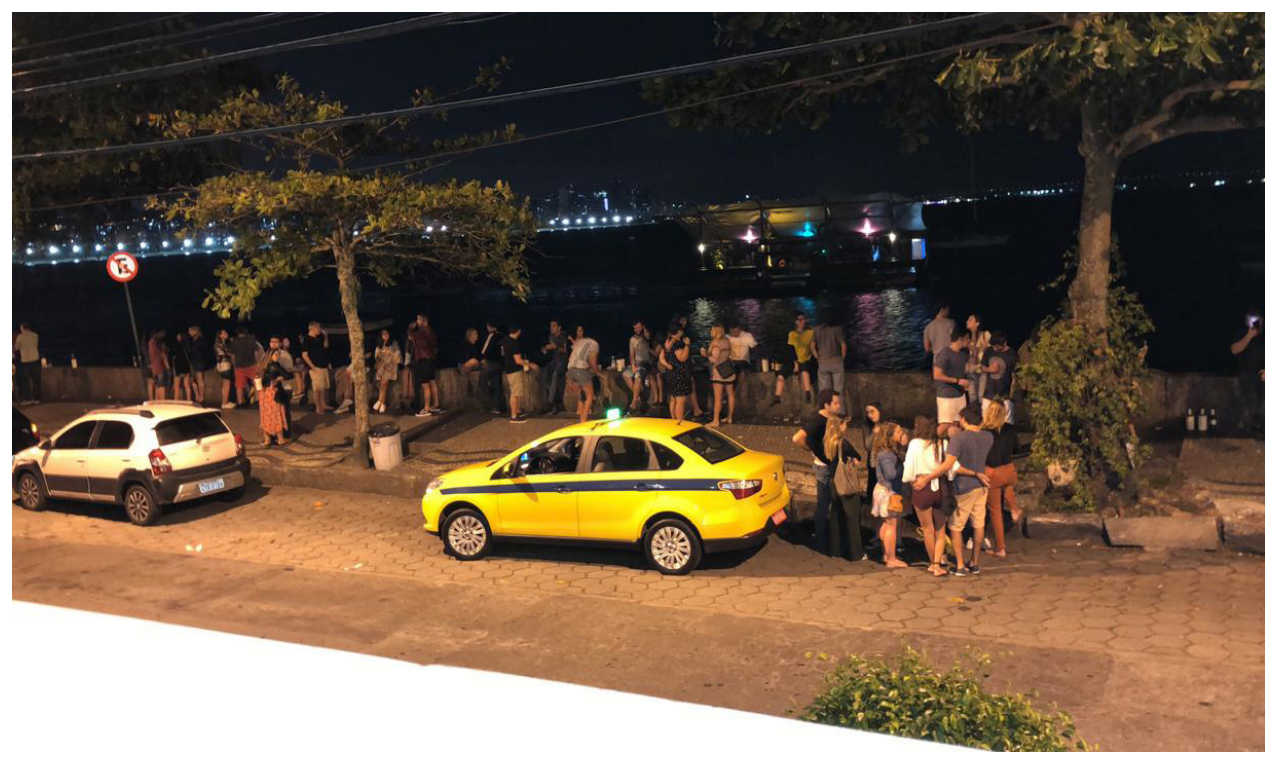

Fotografia 2: Vista noturna da Mureta da Urca pelo restaurante

Fonte: Dados da Pesquisa (2018).

O cardápio do restaurante possui algumas opções de couvert, composto por "torradas com manteiga, azeitonas pretas e verdes, pasta e cubos de queijo minas; pratos frios como salada de palmito, salada de palmito com tomate, salada mista, salada de alface tomate e cebola, prato infantil com variadas escolhas entre as quais se incluem carne, batata frita, arroz e feijão, frango, batata frita, arroz e feijão, filé de peixe, purê de batata, arroz e feijão" (Bar Urca, 2018). Além desses, há opções de pratos executivos individuais ou para duas pessoas. Existem também variados pratos à la carte com preços mais altos, que oferecem opções como frutos do mar, bacalhau, filé de peixe, pratos vegetarianos individuais. No restaurante também são vendidos petiscos próprios do bar Urca, sobremesas, além de bebidas como vinhos, espumantes, cerveja, refrigerantes, sucos e drinks.

O movimento no restaurante no horário do almoço é marcado pela presença de muitas famílias que circulam pelo ambiente e permanecem nele por bastante tempo, conversando e convivendo com seus familiares. Alguns interagem com outros frequentadores, o que sugere se tratar de frequentadores habituais. Entre os poucos jovens no espaço do restaurante, foi observado alguns sozinhos e outros acompanhados em casais. O restaurante possui uma sonorização agradável, um bom atendimento ao cliente e uma boa comida. 
As observações permitiram perceber que mesmo se tratando do mesmo estabelecimento, a diferença proporcionada pelo ambiente sugere a elaboração de uma identidade própria ao restaurante. Além do ambiente, o próprio serviço demarca essa diferenciação. Ao ser solicitado o cardápio, questionou-se se este é o mesmo do bar, e a informação obtida foi de que cada espaço possuía seu próprio cardápio. Como Jenkins (2005) sublinhou, o processo de construção identitária é um constante esforço de "ser" e "se tornar" e, como os dados colhidos na observação sugerem, existe um movimento de diferenciação entre o bar e restaurante, revelando uma identidade própria de cada espaço ao consumidor. As características mencionadas por Mello (2003) sobre a identidade dos bares e botequins cariocas são afastadas para experiências de consumo proporcionadas no restaurante. Por ser um ambiente mais requintado, o espaço sugere um incentivo que as práticas de consumo sejam direcionadas para um público distinto ou em situação mais diferenciada (Bourdieu, 1979). Como observado por Sebadelhe (2016), a experiência que se pretende gerar é fundamental para o entendimento do significado do consumo entre bares e restaurantes no cenário carioca, tendo em vista as variações de objetivos e interesses dos proprietários e dos próprios consumidores.

No ambiente do restaurante, a socialização se dá na mesa, entre amigos e familiares. Alguns pedem pratos para almoçar ou jantar, outros para petiscar, alguns acompanhado pela mesma cerveja consumida na mureta, enquanto outros optam por outro tipo de bebida, seja esta bebida alcoólica ou não. Há ainda grupos de frequentadores que marcam reuniões de trabalho no restaurante e, ao término, alguns vão para mureta. Essa observação vai ao encontro dos achados no estudo de Araujo, Rocha, Chauvel e Schulze (2013), que destacaram que as escolhas de lazer incluem práticas comportamentais que não estão dissociados das atividades que demandem responsabilidades, mas podem ser articuladas a essas. Segundo as informações prestadas por um dos frequentadores, a escolha do restaurante já foi pensada considerando "esticar" para a mureta após o término da reunião de trabalho. Dessa forma, quando isso acontece, o grupo já vem preparado para participar do encontro de lazer após a atividade profissional. Observou-se ainda que os consumidores do restaurante utilizam vestimentas mais formais, tendo em vista que o público frequentador desse ambiente tende a ser mais maduro. Segundo os entrevistados que frequentam o restaurante, esta se torna uma opção interessante quando é necessário realizar atividades de trabalho, em razão do ambiente não ser tão ruidoso como na mureta, além de ser confortável para realização de uma reunião. Por essa razão, os consumidores que frequentam o restaurante são indivíduos em situações mais formais, que buscam o local para almoço de família ou com o companheiro, reuniões de trabalhos, ou turistas que buscam fazer uma refeição mais completa.

(3) Mureta: A Mureta da Urca é um nome dado pelos consumidores do bar ao espaço do outro lado da calçada na orla da Urca situado em frente ao Bar e Restaurante Urca, que possui um pequeno muro em que as pessoas se encontram para interagir e socializar. A mureta fica próxima à entrada da área militar do exército de acesso ao Forte São João e possui uma belíssima vista de Baía de Guanabara. Nesse espaço, pode-se observar 
uma intensa socialização entre os consumidores, diversos grupos de jovens, com diferentes perfis e idades, além de pessoas de idades mais adultas. Os frequentadores aparentavam ser indivíduos de classe social média/alta que, no geral, vão à mureta com vestimentas mais leves e informais. Muitos deles usavam roupa de praia, chinelo, outras pessoas de roupas fitness, enquanto outros estavam mais arrumados, porém ainda com vestimentas leves e informais.

Na mureta, o público se mistura, pois diferentes grupos de pessoas interagem uns com os outros, como se a sociabilidade praticada entre os indivíduos completasse a função do espaço. Durante as entrevistas foi possível observar que, recorrentemente, os informantes observam o local para saber se estavam chegando mais jovens para tentar se integrar.

O público que frequenta a Mureta da Urca é relativamente heterogêneo. Encontram-se no espaço casais com ou sem crianças e de todas as idades; homens e mulheres desacompanhados; grupo de amigos em geral; colegas de trabalho no pós-expediente; turistas; idosos; jovens; estudantes em saída da escola etc. O movimento da mureta se articula com o consumo do bar e se apresentou constante durante todo o tempo das visitas, tendo aumentado próximo às $17 \mathrm{~h}$, quando percebeu-se um número grande de pessoas que saíam do trabalho e paravam com seus colegas para um típico happy hour. Presenciou-se um fato que pode ilustrar bem a cultura da boemia carioca, quando um grupo de pessoas chegou, em uma tarde normal de observação após às 17h, todos vestidos formalmente, incluindo terno, estacionaram os carros e trouxeram violão, iniciando uma seresta, enquanto bebiam e conversavam sentados na mureta.

Assim, os indivíduos buscam a mureta por motivos variados, como descontração, encontros pós-expediente, paqueras, passeio turísticos, passar tempo com os amigos tomando cerveja e alguns até mesmo para discutirem seu relacionamento. Não raro, há quem vá sozinho para contemplar a vista, passar o tempo, e usa o celular para interagir com outras pessoas. Interessante perceber que os indivíduos parecem não se importar com a presença de outros tão próximos, tendo em vista que não existe mesa ou cadeira, o que, supreendentemente, não torna o local desconfortável em razão de outras variáveis, bem como o conjunto de significados que formam o capital simbólico do lugar, mediando relações, compensações, interesses e produção de sentidos. Alguns consumidores pontuaram sua experiência como frequentadores da Mureta da Urca, dentre os quais destacamos o seguinte depoimento:

Final de tarde e noite, fico em média 3 horas... Geralmente quando venho aos sábados é para comemorar aniversário ou alguma despedida de amigos. Quando venho no domingo é para curtir o final do fim de semana com um lindo pôr do sol e uma cervejinha. O horário é pelo pôr do sol. 


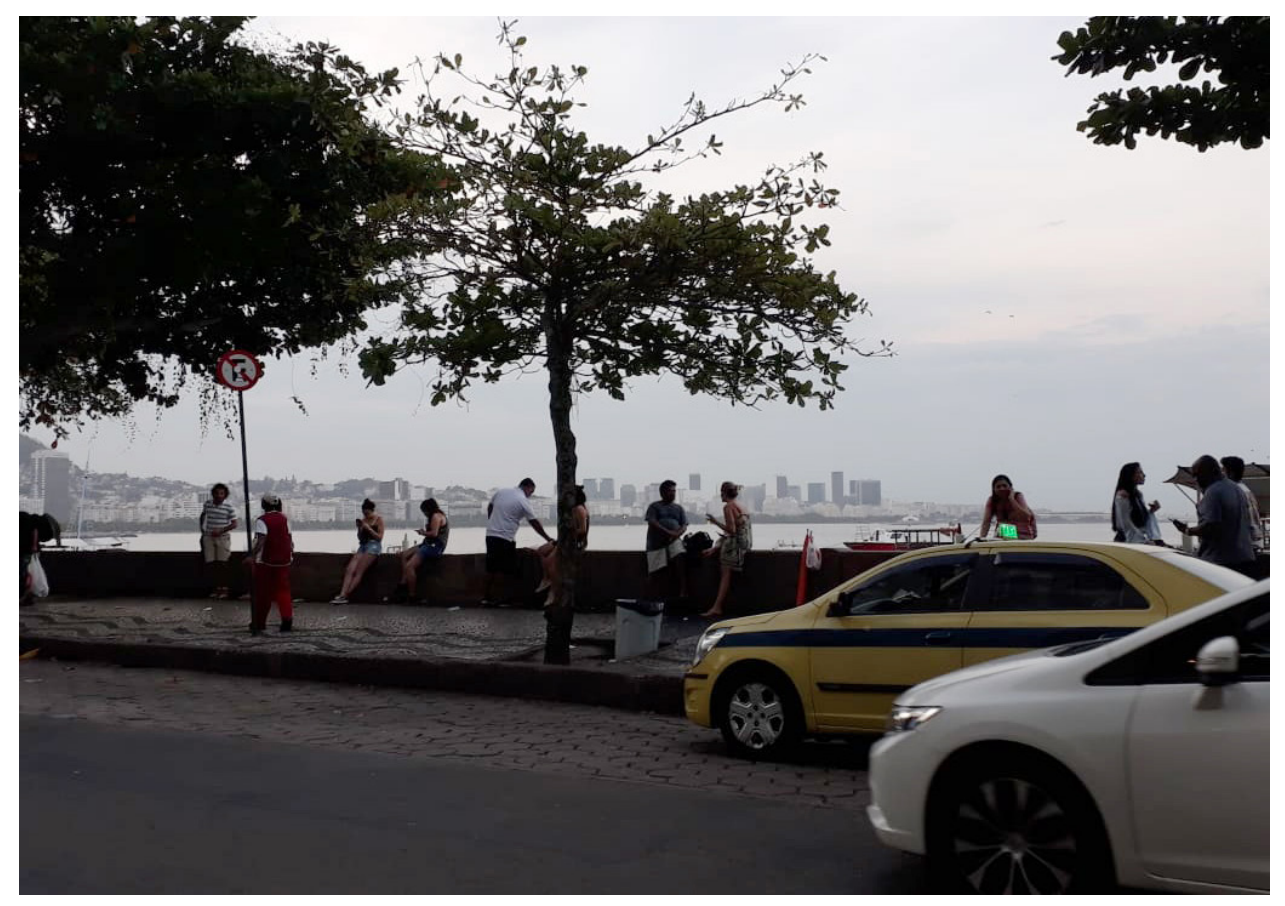

Fotografia 3: A Mureta da Urca vista da entrada do bar no início da tarde Fonte: Dados da Pesquisa (2018).

Muitos dos consumidores do primeiro andar do Bar e Restaurante Urca, como essa parte do estabelecimento não possui mesas, optam por fazer seu pedido e escolhem o espaço da mureta para sociabilizar com os seus amigos, uma vez que esta é bem em frente ao bar. Durante as observações percebeu-se que esses consumidores são formados, em grande parte, por grupo de amigos que vão à mureta da Urca para aproveitar o tempo livre e ficar conversando ali em pé na calçada ou na mureta. Quando o seu pedido fica pronto, esses consumidores levam os seus petiscos e sua cerveja para Mureta do outro lado da rua. As cervejas são entregues, por vezes, com objeto apelidado de "camisinha" (objeto para manter a temperatura da cerveja). Ao receberem as cervejas, estas são colocadas no chão ou apoiadas na mureta.

Chama a atenção a forma própria de atendimento dos frequentadores da mureta que desejam consumir os petiscos e a cerveja. Os consumidores podem solicitar o cardápio do bar na mureta, que podem ir ao bar do outro lado da rua para fazer o pedido, mas o bar também disponibiliza um garçom que faz o movimento de atravessar a rua para recolher pedidos e levar os petiscos aos consumidores. Entretanto, aos finais de semana, nos horários de muito movimento, esse serviço é suspenso, uma vez que o bar não tem pessoal para atender todo o fluxo de movimentação de pessoas nesses casos. Nessa situação, os consumidores devem ir ao caixa do bar e quando o pedido fica pronto, o garçom grita o pedido para que o consumidor venha buscar os petiscos e as bebidas compradas. Há também um funcionário para recolher as garrafas de cerveja, que transita de tempos em tempos pela calçada da mureta recolhendo as garrafas vazias.

Apesar da mureta funcionar como uma espécie de "mesa" para o bar e existir um grande fluxo de pessoas consumindo petiscos e bebidas, o 
espaço é bastante limpo. Existem lixeiras públicas espalhadas pela calçada da mureta e os frequentadores preservam a limpeza do lugar.

Uma consumidora alemã, em turismo pela cidade, destacou que "o melhor do lugar é o visual". A turista pontuou que, para ela, o que diferencia este bar dos outros é a vista da Baia de Guanabara. A narrativa da consumidora reúne o bar e a mureta da Urca como um mesmo lugar, com se um fosse extensão do outro.

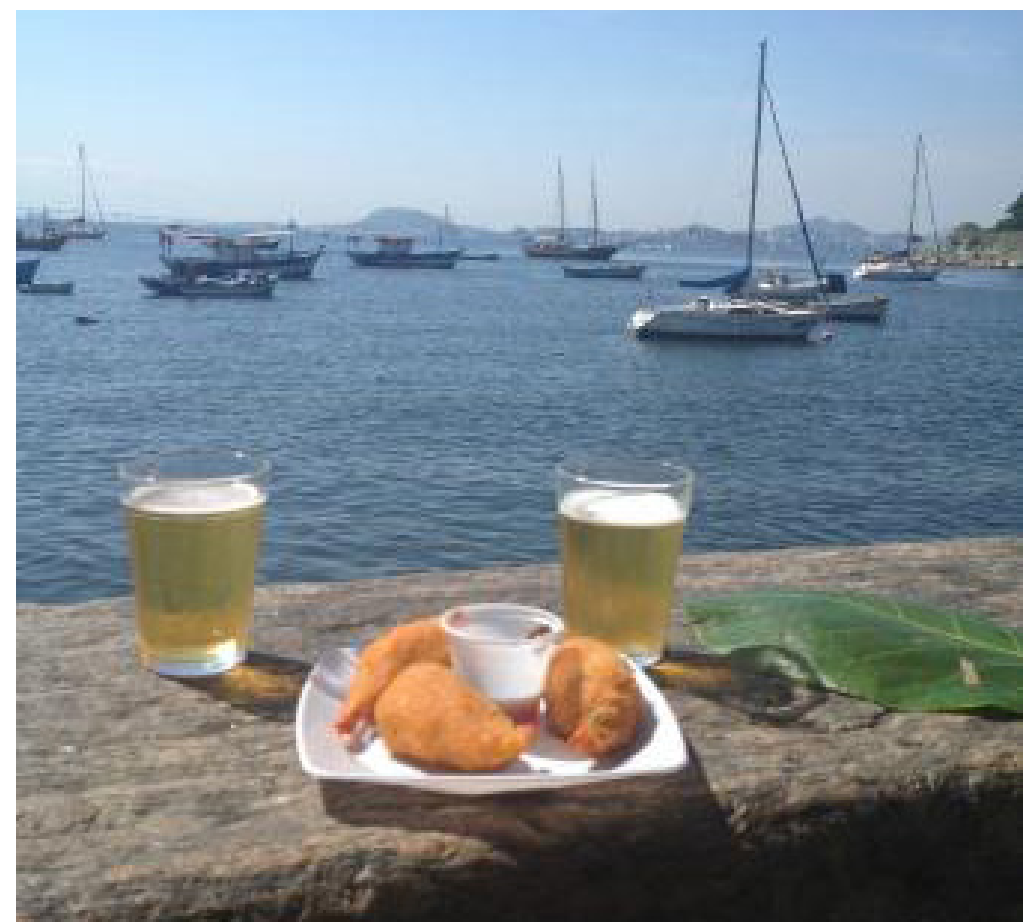

Fotografia 4: Alimentos e bebidas sobre a mureta

Fonte: Acervo do site Trip Advisor Brasil. Publicada em 28/05/2015.

Um jovem consumidor carioca destacou que o espaço é tradicional, tratando-se de um importante ponto turístico da cidade do Rio de Janeiro. Em suas palavras:

Costumo frequentar o bar Urca e mureta aos domingos, uma vez por trimestre. Geralmente, no final da tarde, pós-praia. Fico por aqui umas 4 horas para ver o pôr do sol, comer pastel e beber cerveja gelada com os amigos... O bar Urca eu frequento por ser tradicional, acho que ele tem uns 100 anos, é 'mega' [muito] tradicional, está na lista do roteiro turístico! E a mureta pela vista.

No mesmo sentido, um outro jovem, também morador da cidade do Rio e frequentador assíduo, fez um relato parecido com o anterior em que sugere perceber o bar e a mureta da Urca como espaços distintos. Para ele, a motivação de frequentar o bar é pela comida, enquanto a razão de ficar na Mureta é pela vista que o espaço proporciona.

Eu venho com amigos e namorada. Eu venho mais para comer do que para beber. Como tudo o que tem no Bar Urca. Mas bebo só cerveja, falta um vinho aqui. Para o final de tarde seria ótimo. Um rose gelado ou um branco. Eu gosto de tomar vinho e comer empadas, pastéis e bolinhos..." 
equ a vista, porque os bares não são muito bons. A mureta é mais para jovens e lá [restaurante] já tem um pouco mais de família... Os jovens ainda ficam aqui, em maior parte!

Destaca-se que este não foi o único frequentador que mencionou ir ao Bar Urca para comer, fato que contraria a percepção geral de outros informantes de que a Mureta seria um lugar em que "as pessoas se encontram para beber e conversar". Conforme se depreende pelos depoimentos, existe um conjunto de apelos que contribui para a frequência do lugar, como a comida, a vista, o pôr do sol, a sociabilidade, o turismo, conhecer pessoas, entre outros. Assim, embora a interação com os amigos e a cerveja também sejam apelos frequentemente mencionados, existem outros que também se mostram relevantes para as práticas de consumo dos frequentadores.

Um jovem morador do bairro da Urca mencionou que frequenta a mureta recorrentemente em razão da proximidade de sua casa, porém destacou que come pouco em razão dos preços, optando por consumir cerveja. Porém para o jovem, o mais importante é o consumo do lazer, representado na forma de socialização e interação com os amigos.

\begin{abstract}
Eu frequento bastante! .... Frequento bastante o bar Urca pelo menos umas 4 vezes no mês. Existe o restaurante e o bar mesmo. Mas eu vou no bar compro cerveja e venho beber na mureta. Só venho para beber, mas acabo comendo uns petiscos que são bons, mas bem caros. Bebo só a cerveja.... De comida, sempre como pastel e bolinho de bacalhau. Quando resolvo comer, porque geralmente venho só para beber.

O que me faz vir aqui sempre é a cerveja gelada, o ambiente é super agradável, típico carioca. Ah o ponto negativo é que a cerveja é caríssima e, às vezes, fica muito cheio. Geralmente, venho com a galera que mora na minha rua, pela proximidade sempre tem alguém conhecido aqui. Ambiente agradável, muito relaxante ficar bebendo aqui na mureta com essa vista.
\end{abstract}

Esse último depoimento destaca elementos da boemia típica do carioca, que de certa forma estão presentes em espaços como bares e botecos da cidade, tendo aparecido também no Bar Urca, mais especificamente pelos consumidores no espaço da mureta. Conforme verificado por Silva (2011), os bares e botecos são os espaços dos encontros que fomentam relações e interações sociais, criam e mantêm símbolos e significados. A mureta, que representa "o espaço de interação social" por excelência do Bar Urca, faz o papel simbólico da mesa do bar, trazendo para si o lugar da sociabilidade que é mediada pelas práticas de consumo de comidas e bebidas ali experimentadas. Como mencionado por Barbosa (2010), o prazer existencial do encontro é muitas vezes o elemento central proporcionado pela sociabilidade quando se come e bebe em companhia, fenômeno este claramente presente no caso dos consumidores do Bar Urca.

Um elemento importante presente nas práticas de consumo dos frequentadores da mureta da Urca é o lazer. Araujo e Rocha (2016; 2019), Liechty, Genoe, \& Marston (2017) e Matsunobu (2018) observam que o consumo de lazer está relacionado com a realização de atividades socialmente compartilhadas, que são praticadas pelos indivíduos por gerar prazer, diversão e satisfação. Essas características estavam fortemente presentes nas observações e também estavam marcadas de diferentes formas nas percepções narradas pelos frequentadores da Mureta, as quais 
os pesquisadores tiveram acesso neste estudo. Desse modo, os resultados que emergem na presente pesquisa permitem perceber que o consumo de lazer integra as práticas de consumo no bar, que são mediadas pela beleza geográfica e pelo espaço de convívio social da mureta da Urca.

(4) Pobreta: Um espaço que emergiu no discurso de vários entrevistados durante a observação na Mureta da Urca foi um lugar chamado por eles de "Pobreta". O espaço em que fica a parte da mureta chamado de pobreta é em frente ao bar e restaurante Urca Grill. O apelido foi dado pelos próprios frequentadores da região em razão do preço praticado pelo consumo da cerveja, que é mais barato, além de oferecer petiscos simples e mais em conta, como gurjão de peixe ou frango (Cavalieri, 2014). O espaço tem atraído a frequência dos consumidores em razão do preço e de que, em certas ocasiões, o local da tradicional Mureta fica muito cheia de clientes e de turistas. Nesse sentido, o espaço apelidado de pobreta se torna uma opção alternativa para os consumidores interessados em tomar cerveja e comer uma comida típica de bar carioca, enquanto interagem com os amigos, dispondo da vista para Baia de Guanabara.

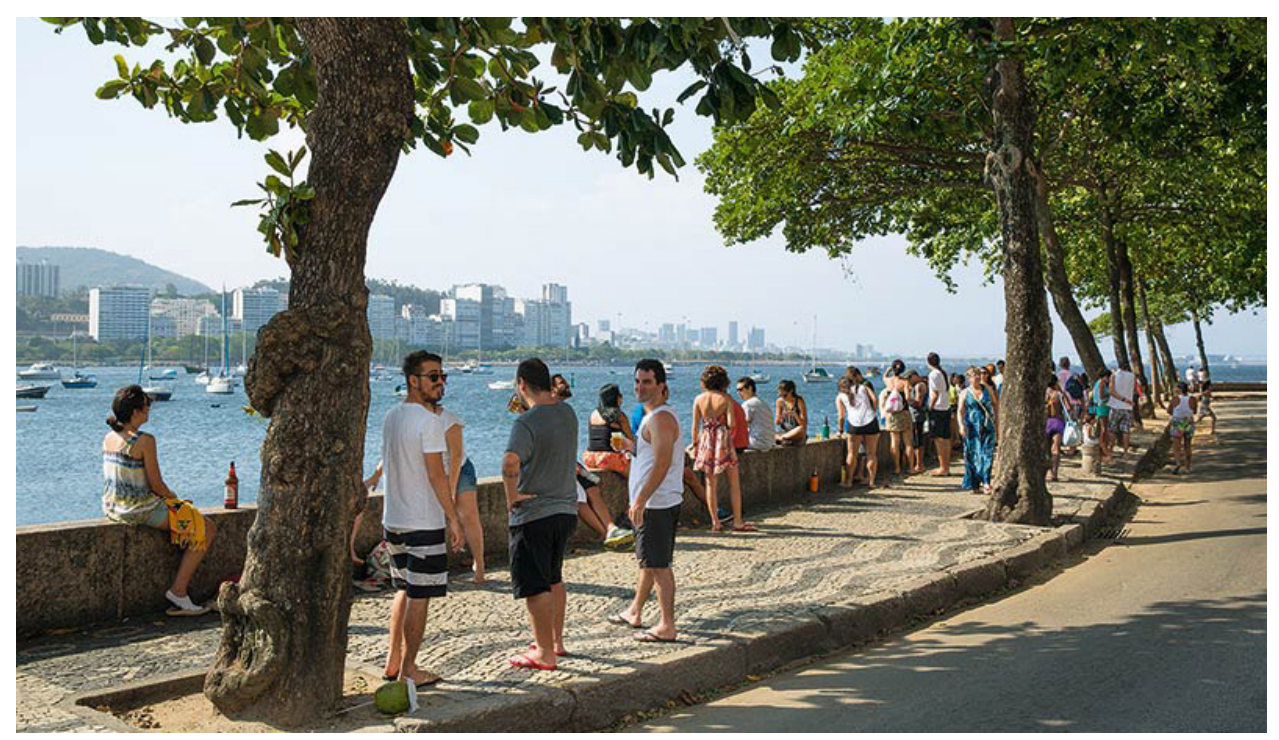

Fotografia 5: Região da Mureta da Urca apelidada de "Pobreta"

Fonte: Felipe Fittipaldi in "Cavalieri, Rafael. Conheça o outro lado da Mureta da Urca". Veja Rio. Publicado em 08/11/2014.

O espaço a que se refere à pobreta disputa, de alguma forma, os consumidores com o espaço onde fica a mureta tradicional que está mais próximo ao Forte São João. A pobreta dispõe do mesmo visual e do pequeno muro em que os consumidores podem sentar-se ou colocar o petisco e a cerveja. Por ficar na área da mureta mais próxima da praia da Urca, o bar localizado na área chamada pobreta divide seus clientes com ambulantes, que transitam entre a praia e esse espaço.

As observações realizadas permitiram concluir que a pobreta se tratou de uma opção para o frequentador da mureta da Urca experimentar e usufruir de outras opções dessa área, por também oferecer uma belíssima vista, que veio a se tornar a mais popular opção alternativa para manter o hábito, 
porém de um modo mais econômico. Destaca-se que o preço emerge no discurso dos informantes como algo preponderante. A possibilidade de usufruir dessa prática de consumo, que envolve lazer e sociabilidade, é fomentada pelos diversos aspectos simbólicos que permeiam o espaço, mas que encontra no fator preço um limitador. Essa relação entre o desejo de frequentar um espaço de encontro com amigos, com as características que a mureta da Urca oferece, e o preço praticado no bar, sugere a abertura para outras possibilidades, permitindo surgir o espaço conhecido como pobreta, justamente por ser economicamente mais acessível. Por essa razão, é comum alguns frequentadores do entorno da mureta onde fica o Bar Urca irem interagir no local, mas não necessariamente consumirem no bar, ou levarem bebidas em caixas térmicas ou de isopor e consumirem apenas os petiscos do bar. Nesse aspecto, os achados deste estudo vão ao encontro da discussão trazida por Luedicke, Thompson e Giesler (2010), que destacam que o valor da identidade de uma marca aumenta junto aos consumidores quando consideram adequadamente os significados ideológicos e os recursos do mercado. Em seu estudo, os autores observaram os efeitos para identidade da marca Starbucks diante de práticas comerciais consideradas predatórias e prejudicais aos cafeicultores por consumidores ativistas. No estabelecimento estudado, o preço praticado, sobretudo para bebidas, pode gerar efeitos na percepção do consumidor, que afetam o valor em relação ao consumo no bar e criam opções alternativas para manutenção da prática de consumo. Um jovem entrevistado que reside na Urca compartilhou com os pesquisadores:

Então, existe a pobreta e a mureta. A pobreta é lá no começo da Urca e a galera frequenta o Bar Urca Grill. O Bar Urca em si é essa mureta aqui que fica localizada no final da Urca perto do Forte, o ponto negativo é que aqui a cerveja é caríssima e, às vezes, fica muito cheio... Por isso, eu frequento os dois.

Um outro informante complementa a ideia:

Eu frequento aqui o Bar Urca e a Mureta, mas às vezes escolho a pobreta pela vista melhor e cerveja mais em conta. Porém aqui a comida é melhor. A pobreta é um ponto específico, em frente à cabine de polícia, sabe? No trevo.

Costumo frequentar sábado ou domingo, uma vez no mês. Geralmente, venho depois de uma atividade diurna... escalada, praia, corrida. Costumo frequentar com amigos ou com algum flerte. Venho só beber.... Os motivos são o visual, o clima descontraído e o preço, nessa ordem.

O fato de ter surgido um espaço alternativo permite compreender que os significados do consumo, no caso da mureta, estão fortemente demarcados no lugar da interação e da sociabilidade. Como mencionado por Araujo e Rocha (2017), o processo de significação pode sofrer descolamentos, gerando novas percepções ou ressignificações, quando novos aspectos das práticas de consumo surgem das interações sociais. Kozinets (2001) destacou que as práticas de consumo também resultam da criação de sentido decorrentes das experiências, que são culturais e possuem aspectos simbólicos, ritualísticos, estéticos e hedônicos, sendo esta última fortemente relacionada às atividades de lazer. No caso das práticas de consumo da mureta, além da sociabilidade, o lazer emerge como um dos elementos centrais, apesar de não mencionado diretamente. Trata-se do elo que articula 
a facilidade de acesso e interação social entre os indivíduos ao consumo de bebida e da comida. Por essa razão, foi possível deslocar o espaço físico do "estar" na mureta, pois os elementos centrais dessa prática de consumo acompanharam o movimento. Contudo, houve uma ressignificação do novo espaço da mureta, que passa a ser percebido como pobreta, representando uma maneira dos próprios consumidores estabelecerem uma diferenciação social entre os espaços (Bourdieu, 1979), considerando as características próprias das relações de consumo estabelecidas nesse outro ambiente.

\section{Considerações Finais}

Este trabalho procurou compreender o processo de criação de significados por meio das práticas de consumo em bares e botecos, tendo sido escolhido para realização empírica da pesquisa o tradicional Bar e Restaurante Urca, conhecido popularmente como o bar da Mureta da Urca. De acordo com Arnould e Thompson (2005), considerando que o consumo é um fenômeno complexo, simbólico e cultural, as pesquisas interpretativas que promovem o diálogo entre consumo e cultura realizam uma importante contribuição para área de comportamento do consumidor. Essas experiências de consumo, o ambiente e as interações favorecem a construção de uma identidade própria dos bares e botecos, além de contribuir para formar um conjunto de significados do chamado "espírito carioca".

A partir das observações feitas e do discurso dos frequentadores, emergiram quatro diferentes categorias de análise, a saber: bar, restaurante, mureta e pobreta. Essas categorias dizem respeito ao espaço onde ocorrem as práticas de consumo, que reúnem diferentes significações estabelecidas pelas interações sociais dos frequentadores. A percepção do que é tipicamente expressão da boemia carioca é fortemente identificada no discurso dos consumidores, sendo, inclusive, mencionado por alguns dos frequentadores da mureta da Urca.

A pesquisa permitiu constatar que o campo da alimentação e bares tradicionais oferece interessantes perspectivas para se pensar o consumo a partir das interações sociais e simbólicas apresentadas nesse contexto. Observou-se que existe um conjunto de apelos que contribuem para frequência do lugar, tais como a comida, a vista, o pôr do sol, o rito de socializar e conhecer pessoas, conversar com amigos, tomar a cerveja, comer petiscos. Essas práticas estabelecem uma rede de sociabilidades mediada pelo espaço de convívio na mureta. Esses achados corroboram com os resultados da pesquisa de Barbosa (2010), que constatou que o significado último das associações entre a sociabilidade e os momentos de alimentação com conjunto é o prazer existencial do encontro e da interação social entre os consumidores. Nesse sentido, a sociabilidade emerge como um elemento central.

As observações permitiram compreender que a mureta representa algo como a mesa do bar para os consumidores do bar Urca e abre espaço para ações de sociabilidade entre os frequentadores. Desse modo, a mureta surge como uma extensão do próprio bar para uns, ou como um espaço próprio em que se prefere estar para consumir a bebida e a comida comprada no bar. 
Contudo, a mureta é o principal espaço de socialização dos consumidores do bar. Essa pode ser a razão que explica o bem-sucedido surgimento do espaço alternativo chamado de pobreta, pois apesar do deslocamento do espaço físico do "estar" na mureta, esse deslocamento carregou consigo o lugar da interação social e da sociabilidade.

Assim como identificado no estudo de Araujo e Rocha (2019), a relação entre a sociabilidade e o lazer praticado pelos frequentadores da Mureta da Urca pode ser mediada pelo consumo de atividades que nascem das experiências e das práticas culturais socialmente construídas e compartilhadas. O lazer também aparece como um importante elemento entre os significados do consumo presentes no Bar Urca, pois assume características localizadas em grupos e nos locais específicos como a comida, a bebida, a conversa, o encontro, os amigos, o prazer de estar na mureta e da apreciação da vista do lugar, as quais são associadas também ao pertencimento da própria identidade carioca. Essas práticas de consumo corroboram com Mello (2003), em relação ao que o autor designa como desenvolvimento de cultura de bar, reconhecida como uma forma de lazer típica da cidade do Rio de Janeiro. Assim, nesta pesquisa, observou-se que tal fenômeno foi resultado de uma dinâmica própria, que se encaminhou pela articulação da cultura local com os significados socialmente construídos a partir das opções de consumo.

Por fim, espera-se que esta pesquisa traga subsídios aos pesquisadores acadêmicos de estudos de consumo e cultura, além de identificar novas oportunidades de pesquisa sobre a sociabilidade o lazer e os espaços populares de interação social, como os bares. O estudo possui limitações, pois como se trata de uma análise de natureza qualitativa, não sendo possível a generalização empírica dos resultados. Apesar dos esforços empregados na pesquisa, houve ainda dificuldades para o recrutamento de entrevistados durante o processo de campo no Bar e Restaurante Urca, o que prolongou o trabalho de campo. Apesar das limitações, apresenta-se contribuições relevantes sobre características de consumo do ambiente estudado. Ademais, contribui-se para o conhecimento de aspectos que impactam do comportamento do consumidor desses espaços, pois refletem as imagens valorizadas pelo consumidor e transferem significados que forma o capital simbólico do espaço. Para avançar na discussão dessa temática, sugere-se que novas pesquisas sejam realizadas de modo que a investigação de aspectos culturais sobre as práticas de consumo em bares, restaurantes e outros espaços que promovam a relação entre alimentação, sociabilidade e lazer possam contribuir para o avanço do conhecimento do tema a partir da perspectiva de análise da cultura e do consumo.

\section{Referências}

Adade, D. R. (2013). "Comida de buteco": O botequim, um pedaço da alma carioca, em uma iniciativa de construção de comunidade virtual de marca. Dissertação de Mestrado, Escola Brasileira de Administração Pública e de Empresas, Rio de Janeiro, RJ, Brasil. 
Ahuvia, A. C. (2005). Beyond the extended self: loved objects and consumers' identity narratives. Journal of Consumer Research, 32(1), 171-84.

Appadurai, A. (1990). Introduction: commodities and the politics of value. In A. Appadurai (Ed.). The social life of things (pp. 3-63). Cambridge: University Press.

Araujo, F.F., Cherchiaro, I.B., Silva, R.C.M., \& Espíndola, R.S. (2020). Experience marketing in large events: an exploratory study at Rio 2016 Olympic Games. Journal of Development Research, 10(1), 36757-36765. DOI: 10.37118/ijdr.19030.06.2020.

Araujo; F.F., Bitar, N.P., Santos, M.M.A.S., Baião, M.R. \& Silva, T.C. P. (2019). Experiências de consumo no samba: um estudo sobre o processo de significação da Feijoada Portelense. Alceu, 20(38), 142-163.

Araujo, F. F., \& Rocha, A. (2019). The redefining of later life through leisure: music and dance groups in Brazil. Leisure Studies, 38(5), 712727. DOI: 10.1080/02614367.2019.1636847.

Araujo, F. F., \& Rocha, A. (2017). Ressignificação da terceira idade: redescobrindo corpo, prazer, vida e sociabilidade na Dança de Salão. In XLI Encontro da ANPAD Encontro da Associação Nacional de Pós-Graduação e Pesquisa em Administração. São Paulo: ANPAD.

Araujo, F. F., \& Rocha, A. (2016). Significados atribuídos ao lazer na terceira idade: observação participante em encontros musicais. Podium: Sport, Leisure and Tourism Review, 5(2), 38-55.

Araujo, F. F., Rocha, A., Chauvel, M. A., \& Schulze, M.F. (2013). Meanings of leisure among young consumers of a Rio de Janeiro low-income community. Leisure Studies, 32(3), 319-332. DOI: 10.1080/02614367.2012.677055.

Araujo, F.F., \& Tinoco, C. F. A. (2015). Influência da religião no comportamento do consumidor: um estudo exploratório do consumo de produtos judaicos. Alceu, 16(31), 38-61.

Araujo, F. F., Turano, L. M., \& Vieira, F. C. (2019). Subculturas Religiosas de Consumo: Um estudo etnográfico de jovens católicos nas práticas dos Exercícios Espirituais. Consumer Behavior Review, 3(2), 99-119.

Arnould, E., \& Thompson, C. (2005). Consumer Culture Theory (CCT): twenty years of research. Journal of Consumer Research, 31(4), 868-882.

Arnould, E., \& Wallendorf, M. (1994). Market-Oriented ethnography: interpretation building and marketing strategy formulation. Journal of Marketing Research, 31(4), 484-504.

Bar Urca. (2018). Cardápio. Bar e Restaurante Urca. Recuperado em 07 novembro, 2018, de http://barurca.com.br/cardapios/

Barbosa, L. (2010). Food and sociability on the contemporary Brazilian plate. Etnográfica, 14(3), 567-586.

Barbosa, L. (2004). Sociedade de consumo. Rio de Janeiro: Jorge Zahar Editora.

Barbosa, L., \& Campbell, C. (2006) Cultura, consumo e identidade. Rio de Janeiro: FGV Editora.

Bourdieu, P. (1979) La Distinction: critique sociale du jugement. Paris: Les Éditions de Minuit.

Cavalieri, R. (2014). Conheça o outro lado da Mureta da Urca. Veja Rio. Recuperado em 08 novembro, 2018, de https://vejario.abril.com.br/comida-bebida/o-outro-ladoda-mureta-da-urca 
Carù, A., \& Cova, B. (2003). Revisiting consumption experience: a more humble but complete view of the concept. Marketing Theory, 3(2), 267-286.

Chick, G. (1998). Leisure and culture: issues for an Anthropology of Leisure. Leisure Studies, 20, 111-133.

Costa, M. M. C., Salazar, V. S., Alves, L. O., \& Silva, A. C. O. (2019). Baja gastronomía: análisis de la influencia del ambiente sobre la satisfacción de los clientes del Restaurante Reteteu (Recife, Brasil). Estudios y Perspectivas em Turismo, 28(3), 715-735.

Decreto Municipal/RJ no. 36605/2012. Decreto declara Patrimônio Cultural Carioca bares e botequins tradicionais. Rio de Janeiro.

Elliott, R., \& Jankel-Elliott, N. (2003) Using ethnography in strategic consumer research. Qualitative Market Research, 6(4), 215-223.

Ferreira, M. R., Valduga, V., \& Bahl, M. (2016). Baixa Gastronomia: caracterização e aproximações teórico-conceituais. Turismo em Análise, 27(1), 207-228.

Gaião, B.F.S., Souza, I.L., \& Souza Leão, A.L.M. (2012). Consumer Culture Theory (CCT) já é uma escola de pensamento em Marketing? Revista de Administração de Empresas, 52(3), 330-344.

Geertz, C. (1973). A Interpretação das Culturas. Rio de Janeiro: Zahar.

Hall, S. (1997). Representation: cultural representation and signifying practices. London: Open University Press.

Holbrook, M. B., \& Hirschman, E. C. (1982). The experiential aspects of consumption: consumer fantasies, feelings and fun. Journal of Consumer Research, 9, 132-140.

Holt, D. B. (2002). Why do brands cause trouble? A dialectical theory of Consumer Culture and Branding. Journal of Consumer Research, 29(1), 70-90.

Houaiss, A., \& Villar, M.S. (2001). Dicionário Houaiss da Língua Portuguesa. Rio de Janeiro: Objetiva.

Jenkins, R. (2005) Social identity. 3a. ed. London: Routledge.

Kleine III, R.E., \& Kernan, J.B. (1998). Measuring the meaning of consumption objects: an empirical investigation. Advances in Consumer Research, 15, 498-504.

Kozinets, R. V. (2001). Utopian enterprise: articulating the meaning of Star Trek's culture of consumption. Journal of Consumer Research, 28, 67-89.

Liechty, T., Genoe, M. R., \& Marston, H. R. (2017). Physically active leisure and the transition to retirement: the value of context. Annals of Leisure Research, 20(1), 23-38.

Luedicke, M. K., Thompson, C. J., \& Giesler, M. (2010). Consumer identity work as moral protagonism: how myth and ideology animate a brand-mediated moral conflict. Journal of Consumer Research, 36(6), 1016-1032.

Maclnnis, D., \& Folkes, V. (2010). The disciplinary status of consumer behavior: a sociology of science perspective on key controversies. Journal of Consumer Research, 36(6), 899-914.

Matsunobu, K. (2018). Music for life: a Japanese experience of spirituality, ageing and musical growth. Ageing \& Society, 38, 1100-1120.

McCracken, G. (1998). Culture and consumption: new approaches to the symbolic character of consumer goods and activities. Bloomington: Indiana Press University. 
McFerran, B., Dahl, D. W., Fitzsimons, G. J., \& Morales, A. C. (2010). I'll have what she is having: effects of social influence and body type on the food choices of others. Journal of Consumer Research, 36(6), 915-929.

Medeiros, A. (2004). Batuque na cozinha: as receitas e as histórias das tias da Portela. Rio de Janeiro: Senac Rio.

Mello, P T. (2016). Botequim e a cidade. In Mello, P.T. de \& Sebadelhe, Z.O. Memória afetiva do botequim carioca (recurso eletrônico, 1a ed.). Rio de Janeiro: José Olympio.

Mello, P. T. (2003). Pendura essa: a complexa etiqueta na relação de reciprocidade em um botequim do Rio de Janeiro. Dissertação de mestrado, Universidade Federal Fluminense, Niterói, RJ, Brasil.

Oliveira, R.C. (2006). "Olhar, ouvir, escrever". O trabalho do antropólogo. São Paulo: Ed. Unesp.

Rubin, H. J., \& Rubin, I. S. (2005). Qualitative interviewing: the art of hearing data. Thousand Oaks, California: Sage Publications.

Sebadelhe, Z. O. (2016). Origens. In Mello, P.T. de \& Sebadelhe, Z.O. Memória afetiva do botequim carioca (recurso eletrônico, 1a ed.). Rio de Janeiro: José Olympio.

Silva, L. A. M. (2011). O Significado do botequim. Enfoques, 10(1),115-136.

Slater, D. (2002). Cultura, consumo e modernidade. São Paulo: Nobel.

Solomon, M.R. (2016). Comportamento do consumidor: comprando, possuindo e sendo. 11a ed. Porto Alegre: Bookman.

Stacey, M. (1977). Methods of social research. Oxford: Pergamon Press.

Strauss, A., \& Corbin, J. (2008). Pesquisa Qualitativa: técnicas e procedimentos para o desenvolvimento de teoria fundamentada. Porto Alegre: Artmed.

Taschner, B. G. (2000). Lazer, cultura e consumo. RAE - Revista de Administração de Empresas, 40(4), 38-47.

Trip Advisor Brasil. (2018). Da avaliação Vista Privilegiada! de Bar Urca. Trip Advisor Brasil. Recuperado em 04 novembro, 2018, de https://www.tripadvisor.com.br/ LocationPhotoDirectLink-g303506-d1479608-i133952672-Bar_Urca-Rio_de_ Janeiro_State_of_Rio_de_Janeiro.html.

Thompson, C.J. (1997). Interpreting consumers: a Hermeneutical framework for deriving Marketing insights from the texts of consumers' consumption stories. Journal of Marketing Research, 34, 438-455.

Tureta, C., \& Alcadipani, R. (2011). Entre o observador e o integrante da Escola de Samba: os não-humanos e as transformações durante uma pesquisa de campo. RAC - Revista de Administração Contemporânea, 15(2), 71-78.

Vargens, J.B., \& Monte, C. (2001). A velha guarda da Portela. Rio de Janeiro: Manati.

\section{Agradecimento}

Agradecemos às recomendações dos avaliadores do presente artigo, que contribuíram significativamente para o desenvolvimento de nosso trabalho. 